\title{
Effects of Isokinetic Eccentric Training on Lower Extremity Muscle Activation and Walking Velocity in Stroke Patients
}

\author{
Seung-Kyu Park, Je-Ho Kim \\ Department of Physical Therapy, Graduate School, Sehan University, Yeougam-gun, Jeollanam-do, Korea
}

Purpose: The aim of this study was to determine the effects of isokinetic eccentric training (IET) on lower extremity muscle activation and walking velocity according to slow velocity and fast velocity of isokinetic eccentric training in stroke patients.

Methods: Thirty subjects were randomly divided into three groups: experimental group I $(n=10)$, group II $(n=10)$, and control group III $(n=10)$. Each group was provided intervention under three conditions, as follows: isokinetic eccentric training + slow velocity (group I), isokinetic eccentric training + fast velocity (group II), and sit to stand training (group III). The training program was conducted for eight weeks (five times per week; 30 minutes per day). Subjects were measured on lower extremity muscle (vastus lateralis, vastus medialis, gastrocnemius) activation and walking velocity. Analysis of covariance (ANCOVA) were performed for comparison of lower extremity muscle activation and walking velocity between different intervention methods.

Results: Significant difference in lower extremity muscle activation and walking velocity was observed in experimental group I and group II compared with the control group III $(p<0.01)$. Results of post-hoc analysis showed a significant in lower extremity muscle activation and walking velocity in group I compared with group II and group III.

Conclusion: Findings of this study suggest that slow velocity and fast velocity using isokinetic eccentric training may have a beneficial effect on improvement of lower extremity muscle activation and walking velocity in stroke patients.

Keywords: Stroke, IET, Muscle activation, Walking velocity

서 론

뇌졸중(stroke)은 감각과 운동 기능의 손상으로 인해 걷기와 같은 과 제 수행력의 감소로 인하여 기능적인 활동에 제한을 보이고, 사회적 참여(social participation)에 제약을 가져온다.1,2 뇌졸중 환자의 주된 증상인 반신마비는 신체의 한쪽 근력의 약화를 가져오며, 약화된 마 비측 근육은 근육섬유의 특성의 변화로 선택적인 type II 섬유의 위 축과 운동단위의 동원율에 감소를 보인다. 손상된 위운동신경원은 작용근의 동원율 감소를 나타내며, 작용근과 대항근의 수축 타이밍 의 손상으로 인하여 동적인 과제를 시행하는 동안 동시수축의 약화 를 가져온다. ${ }^{4}$

뇌졸중 환자의 약화된 다리 근력은 감소된 한발지지와 조절되지 않은 전방으로의 움직임은 걸음의 비대칭성을 초래하며, 같은 연령대 의 건강한 사람과 비교하여 발디딤기와 한걸음길이, 걷기속도의 감 소를 보여, 걸음능력의 저하를 가져온다. 다리 근력은 걸음수행력 검
사와 유의한 상관관계를 보이며, ${ }^{6}$ 감소된 관절각도와 걷기속도를 증 진시키기 위해서는 넙다리네갈래근, 넙다리두갈래근, 장딴지근의 근 력강화와 유산소 능력을 향상시킬 수 있는 중재가 필요함을 제시하 였다.?

뇌졸중 환자의 근력강화를 위한 다양한 중재방법이 제시되고 있 으며 그 중 등속성 근력강화 훈련은 근육뼈대계 손상 환자의 재활에 서 오랫동안 광범위하게 이용되고 있으며, 최근 중추신경계 손상 환 자의 재활훈련에 잠재적이며, 흥미로운 중재방법으로 소개되고 있 다. ${ }^{8}$ 등속성 훈련은 일정한 속도로 움직이는 근수축의 형태로 관절가 동범위의 모든 범위에서 최대 근수축을 이룰 수 있으며, 등척성 훈련 과 등장성 훈련과 비교하여 관절가동범위의 변화에 대해 동일한 힘 을 생산한다. ${ }^{9} \mathrm{Bae}$ 등 ${ }^{10}$ 은 무릎관절 전치환술 환자 21 명을 대상으로 등속성 훈련 그룹과 등척성 훈련 그룹의 비교에서 등속성 훈련 그룹 이 근력과 관절가동범위에서 유의한 향상을 보였고, Lee 드이은 만성 뇌졸중 환자에게 등속성 동심성 훈련을 중재하여 무릎관절의 폄 토
Received Jul 23, 2015 Revised Aug 16, 2015

Accepted Aug 16, 2015

Corresponding author Je-Ho Kim

E-mail albam20@naver.com
Copylight (C) 2015 The Korea Society of Physical Therapy

This is an Open Access article distribute under the terms of the Creative Commons Attribution Non-commercial License (Http:// creativecommons.org/license/by-nc/3.0.) which permits unrestricted non-commercial use, distribution, and reproduction in any medium, provided the original work is properly cited. 
크의 증가와 균형능력과 걸음, 삶의 질에 향상을 보였다.

편심성 훈련은 최대 탄성으로 인한 최대 근력을 얻을 수 있으며 근 육과 힘줄 계통에 콜라겐을 합성하여 근세포의 생성과 성장의 활성 화를 일으키며, ${ }^{12}$ 동심성 훈련과 비교하여 에너지를 적게 소모하고 심 호흡계에 작은 부하를 일으키기 때문에 편심성 훈련의 필요성을 시 사하였다. ${ }^{13}$ Dibble 등 ${ }^{14}$ 은 파킨슨 환자에게 고강도의 편심성 저항훈련 을 중재하여 걸음능력의 향상과 균형능력 및 삶의 질의 향상을 보고 하였으며, Marcus 등 15 은 당뇨 환자에게 등속성 편심성 훈련과 등속 성 동심성 훈련을 중재한 후 집단간 비교에서 등속성 편심성 훈련 집 단에서 균형과 걸음능력의 유의한 향상을 보였다.

근력의 증가는 근육 수축의 형태와 근육 수축의 속도에 영향을 받 으며 type I섬유는 type I섬유에 비해 속도 의존적이며, 빠른 속도를 이용한 근력강화 훈련은 근육의 단면적 크기를 증가시키며, 느린 속 도를 이용한 근력강화는 마이오신의 결합력을 증가시켜 큰 힘을 발 생한다고 하였다. ${ }^{16,17} \mathrm{Han}$ 과 Lee ${ }^{18}$ 는 저항속도에 따라 넙다리네갈래근 의 근력과 근육의 두께에 유의한 차이를 보고하였고 등속성 근력강 화운동 시 저항속도를 고려해야 한다고 하였다.

이처럼 등속성 근력강화 훈련을 통해 근력과 균형 및 걸음 향상에 대한 연구들은 활발하게 이루어져 왔으나 등속성 편심성 훈련에 대 한 연구는 부족한 실정이며, 편심성 훈련 속도에 따른 효과를 분석한 연구 또한 부족한 실정이다. 따라서 본 연구의 목적은 뇌졸중 환자에 게 등속성 편심성 훈련이 다리 근활성도와 걷기속도에 미치는 영향 에 대해 알아보고 다리 근활성도와 걷기속도를 분석하여 치료적 반 응을 이끌어 내기 위한 효율적인 속도를 규명하고자 한다.

\section{연구방법}

\section{1. 연구대상}

본 연구는 전남 소재의 J 병원에서 뇌졸중으로 인해 반마비 진단을 받 고 기능회복을 위해 치료를 받고 있는 입원환자들 중 실험방법에 대 하여 충분한 설명을 듣고 자발적으로 참여하기로 동의한 30 명을 선 정하였다. 세부적인 선정기준은 뇌졸중 진단을 받고 1년을 초과하지

Table 1. General characteristic of subjects

\begin{tabular}{lccc}
\hline & $\begin{array}{c}\text { Group I }(n=10) \\
\text { Mean } \pm \text { SD }\end{array}$ & $\begin{array}{c}\text { Group II }(n=10) \\
\text { Mean } \pm \text { SD }\end{array}$ & $\begin{array}{c}\text { Group III }(n=10) \\
\text { Mean } \pm \text { SD }\end{array}$ \\
\hline Height (cm) & $166.5 \pm 6.1$ & $165.5 \pm 5.9$ & $166.3 \pm 5.9$ \\
Age (year) & $59.0 \pm 4.1$ & $58.4 \pm 4.2$ & $58.7 \pm 3.8$ \\
Weight (kg) & $64.9 \pm 5.2$ & $64.7 \pm 7.2$ & $65.0 \pm 7.1$ \\
$\begin{array}{c}\text { Stroke duration } \\
\text { (month) }\end{array}$ & $5.4 \pm 1.4$ & $5.3 \pm 1.2$ & $5.3 \pm 0.8$ \\
\hline
\end{tabular}

Group I, isokinetic eccentric training+slow velocity (IET+SV); Group II , isokinetic eccentric training+fast velocity (IET+FV); Group III, sit to stand training (STST).
않은 자, 한국형 간이 정신상태 검사(MMSE-K) 점수가 24점 이상으로 의사소통이 가능한 자, 독립적으로 $10 \mathrm{~m}$ 를 걸을 수 있는 자, 다른 내. 외과적 의학적 질환을 가지고 있지 않은 자로 선정하였다(Table 1).

\section{2. 실험방법}

본 연구는 느린 속도를 이용한 등속성 편심성 훈련군(Group I) 10 명, 빠른속도를 이용한 등속성 편심성 훈련군(Group II) 10명, 앉은자세 에서 서기 훈련을 중재한 대조군(Group III) 10 명으로 각각 무작위 임 의 선정하여 중재 전. 후 다리 근활성도와 걷기속도를 측정하여 분석 하였다.

\section{1) 등속성 편심성 훈련}

본 연구에서는 등속성 편심성 훈련을 위해 근력평가와 근력강화 훈 련을 할 수 있도록 고안된 Eccentron (BTE Technologies Inc, USA)을 이 용하였다. Eccentron은 스크린과 측력계(ergometer)로 구성되어 있고 측력계는 3 마력의 모터와 힘판(forceplate)이 탑재된 두 개의 발판으로 구성되어 근력의 측정과 훈련 시 되먹임을 제공한다. 훈련은 닫힌 운 동형상학적 사슬에서 이루어지며 저속, 중속, 고속의 속도로 음의 일 률(negative work)을 수행하는 동안 엉덩관절, 무릎관절, 발목관절의 편심성 수축을 유발한다. 훈련속도는 1-40 RPM으로 구성되어 있으 며, 1-13 RPM은 느린 속도, 14-25 RPM은 중간 속도, 26-40 RPM은 빠 른 속도로 나뉘어져 있다. 훈련시간은 총 30 분으로 5 session으로 구성 되며 1 session 당 5 분의 훈련과 1 분의 휴식 시간을 제공하며, 5 분의 훈 련 시간 중 앞, 뒤 1 분씩 2 분은 warm up과 cool down 단계로 훈련강도 의 $50 \%$ 의 힘을 가한다. 실험군(Group I, Group II)은 8주 동안 주 5 회, 1 일 30 분의 훈련을 제공받았다(Figure 1).

\section{2) 앉은자세에서 서기 훈련}

앉은자세에서 서기 훈련은 Roy 등 ${ }^{19}$ 의 연구를 바탕으로 대칭적, 비대 칭적 자세로 이루어진 3 가지 훈련자세에서 8 주 동안 주 5 회 시행되며, 1-4주에서는 훈련자세 당 각각 8-10회씩 $4 \mathrm{set}$ 를 수행하였고 점진적으 로 치료적 강도를 증가시키기 위해 5-8주에서는 각각 12-15회씩 $4 \mathrm{set}$

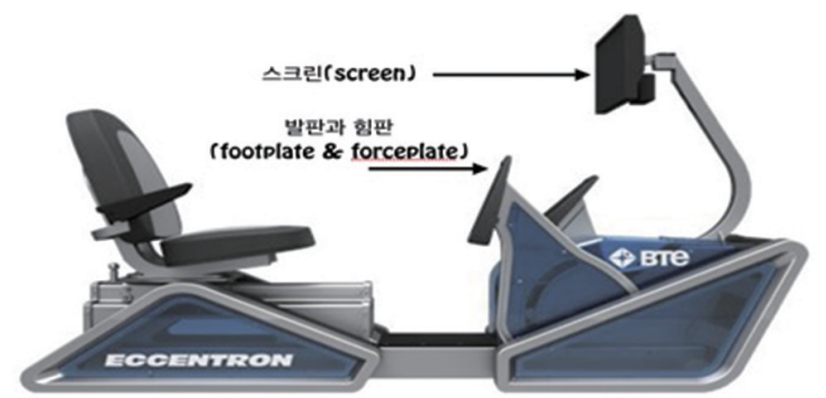

Figure 1. Eccentron system. 
를 수행하였다. 각 set 후 1 분간의 휴식시간을 제공하였다.

\section{3. 측정방법}

1) 표면근전도시스템

다리 근활성도를 측정하기 위해 MP100 표면근전도 시스템(Biopac System Inc., USA)을 이용하였고, 디지털 신호로 변환된 자료는 개인 용 컴퓨터에서 Acqknowledge 3.91 소프트웨어를 이용하여 자료 처리 하였다. 표면근전도 신호에 대한 피부저항을 최소화하기 위해 부착 부위의 털을 제거하고 가는 사포로 3-4회 문질러 피부각질층을 제거 한 후, 소독용 알코올 솜으로 피부를 깨끗이 하였다. 부착 근육은 가 쪽넓은근, 안쪽넓은근, 장딴지근에 부착하였고 이극전극은 각 근육 의 근힘살(muscle belly)에 근섬유의 방향과 평행하게 부착하였다. 표 본추출률(sampling rate)은 $1,024 \mathrm{~Hz}$ 로 설정하였고, 잡음을 최소화하 기 위해 대역 여과 필터(notch filter)는 $60 \mathrm{~Hz}$, 대역 통과 필터(band pass filter) $30-450 \mathrm{~Hz}$ 로 설정하였으며 수집된 신호는 RMS 처리하였다 (Figure 2A).

\section{2) 근활성도의 표준화}

본 연구에서 근활성도를 표준화하기 위해 특정 동작의 근수축을 기 준 수축(reference voluntary contraction, RVC)으로 하여 이를 표준화 하는 \%기준수축(\%RVC)방법을 이용하였다. 반웅크리기 자세(semisquat position)를 5 초 유지하는 동안 측정 근육들의 근활성도를 측정 한 뒤 처음과 마지막 1 초씩을 제외한 3 초의 신호를 분석하여 RVC값 을 산출하였고, 걸음주기의 디딤기 동안 근활성도 값과 비교하여 $\% \mathrm{RVC}$ 값을 산출하였다. 근활성도의 자료는 3 회 측정하여 얻은 결과 의 평균값을 이용하였다.
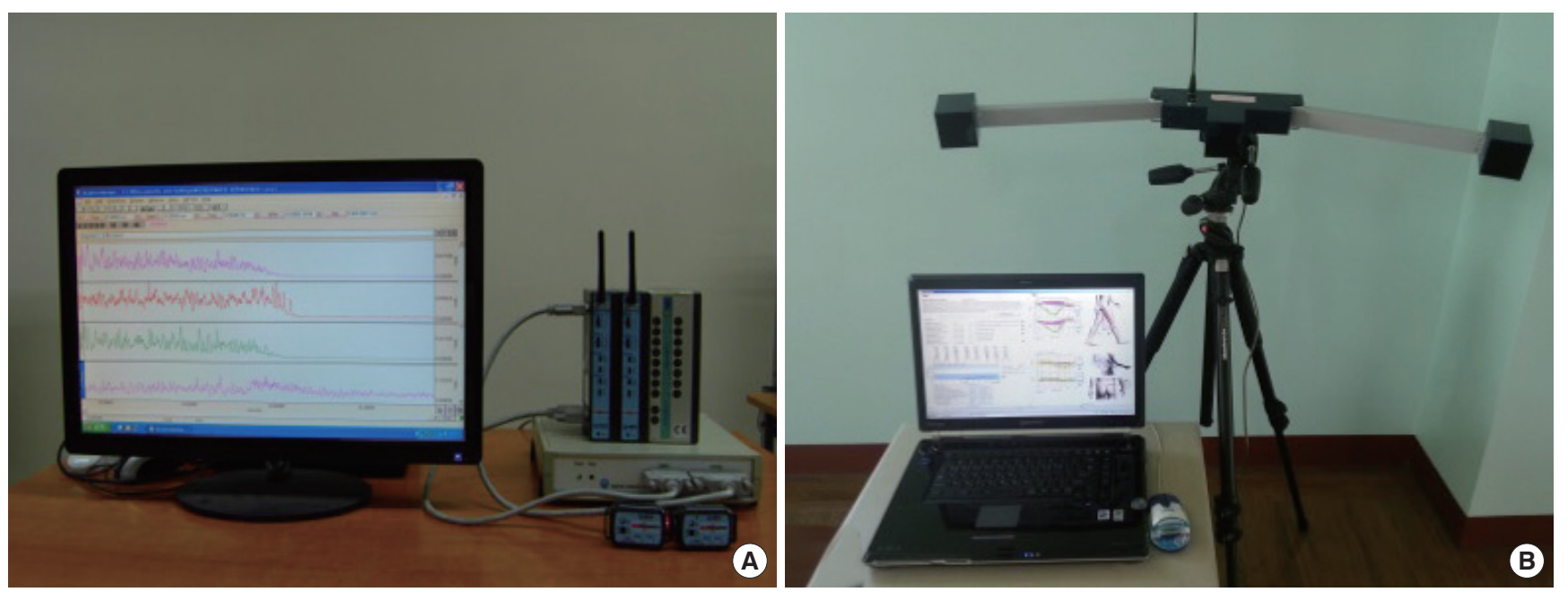

\section{3) 걷기속도 측정}

걸음의 운동형상학적 변인(kinematics variance)과 시간적, 공간적 변 인(temporal \& spatial variance)을 분석하기 위해 LUKOtronic (Lutz-Kovacs Electronic, Austria) 동작분석시스템을 이용하였다. 구성요소는 동작분석을 위한 카메라, 적외선 마커, 분석용 소프트웨어가 내장된 개인용 컴퓨터로 구성되어 있으며, 수집된 데이터는 GaitLab을 이용 하여 분석하였다(Figure 2B).

\section{4. 자료분석}

측정된 자료는 SPSS 19.0 을 이용하여 통계처리 하였으며, 세 집단 간의 동질성 검증을 위해 일요인 분산분석(one-way ANOVA)을 시행하였 고, 중재방법에 따른 그룹 간 다리 근활성도와 걷기속도 차이를 검증 하기 위해 공분산분석을 이용하여 분석하였다. 사후검정으로 Bonferroni 검정을 실시하였다. 통계학적 유의수준은 $\alpha=0.05$ 로 하였다.

\section{결 과}

\section{1. 그룹 간 다리 근활성도 비교}

그룹 간 중재 전후 다리 근활성도 비교 결과, 그룹 I과 그룹 II는 그룹 III와 비교하여 다리 근활성도의 유의한 향상을 보였다 $(\mathrm{p}<0.01)$. 사후 검정 결과 그룹 I은 그룹 II, 그룹 III와 비교하여 다리 근활성도 향상 에 효과적이었다(Table 2).

\section{2. 그룹 간 걷기속도 비교}

그룹 간 중재 전.후 걷기속도 비교 결과, 그룹 I과 그룹 II는그룹 III와 비 교하여 걷기속도의 유의한향상을 보였다 $(\mathrm{p}<0.01)$.사후검정 결과 그룹 I 은 그룹 II, 그룹 III과 비교하여 걷기속도 향상에 효과적이었다(Table 3).

Figure 2. (A) sEMG. (B) Motion capture system. 
Table 2. Comparison of lower extremity muscle activation between groups

(Unit: \%)

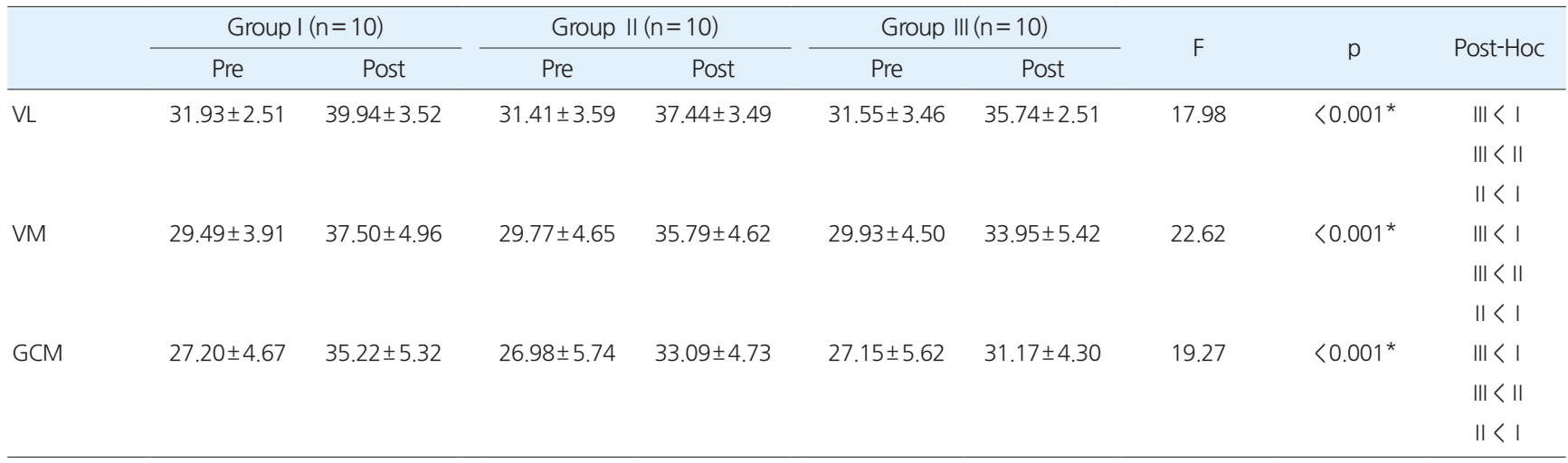

${ }^{*} \mathrm{p}<0.01$

VL, vastus lateralis; VM, vastus medialis; GCM, gastrocnemius.

Group I, isokinetic eccentric training+slow velocity (IET+SV); Group II, isokinetic eccentric training+fast velocity (IET+FV); Group III, sit to stand training (STST).

Table 3. Comparison of walking velocity between groups

(Unit: $\mathrm{m} / \mathrm{s})$

\begin{tabular}{|c|c|c|c|c|c|c|c|c|c|}
\hline & \multicolumn{2}{|c|}{ Group I $(n=10)$} & \multicolumn{2}{|c|}{ Group ॥ $(n=10)$} & \multicolumn{2}{|c|}{ Group III $(n=10)$} & \multirow{2}{*}{$\mathrm{F}$} & \multirow{2}{*}{$p$} & \multirow{2}{*}{ Post-Hoc } \\
\hline & Pre & Post & Pre & Post & Pre & Post & & & \\
\hline \multirow[t]{3}{*}{ wV } & $0.34 \pm 0.04$ & $0.54 \pm 0.07$ & $0.33 \pm 0.05$ & $0.52 \pm 0.06$ & $0.34 \pm 0.05$ & $0.48 \pm 0.05$ & 21.44 & $<0.001^{*}$ & $I I I<1$ \\
\hline & & & & & & & & & $\|I I<\|$ \\
\hline & & & & & & & & & $\|<1$ \\
\hline
\end{tabular}

${ }^{*} p<0.01$.

WV, walking velocity.

Group I, isokinetic eccentric training+slow velocity (IET+SV); Group II, isokinetic eccentric training+fast velocity (IET+FV); Group III, sit to stand training (STST).

\section{고 찰}

편심성 수축은 외적인 토크가 내적인 토크보다 클 때 발생하며 근육 의 길이가 길어지는 수축으로 동심성 수축과 비교하여 더 큰 힘을 생 산하고 산소요구량이 적기 때문에 안전하고 효율적인 훈련방법이 다. ${ }^{20}$ 본 연구는 등속성 편심성 훈련이 뇌졸중 환자의 다리 근활성도 와 걷기속도에 미치는 영향을 확인하고 치료적 반응을 이끌어 내기 위한 효율적인 속도를 규명하기 위해 연구한 결과, 등속성 편심성 훈 련이 대조군과 비교하여 다리 근활성도와 걷기속도에 유의한 향상 을 보였고, 사후검정 결과 느린 속도를 이용한 등속성 편심성 훈련이 다리 근활성도와 걷기속도 향상에 효과적임을 알 수 있었다.

Clark와 Patten ${ }^{21}$ 는 뇌졸중 환자 34 명을 대상으로 등속성 편심성 훈 련군과 등속성 동심성 훈련군으로 나누어 5 주 동안주 3 회 중재한 후 집단 간 비교 결과 등속성 편심성 훈련군에서 넙다리곧은근, 안쪽넓 은근의 근활성도가 유의한 증가를 보였다. Jegu 등2은 무릎관절의 골 관절염을 가진 80 명의 환자를 대상으로 등속성 편심성 훈련군과 등 속성 동심성 훈련군으로 나누어 6 주 동안 주 2 회, 1 일 12 session의 무 릎관절 굽힘과 폄을 중재한 결과 등속성 편심성 훈련군의 넙다리네 갈래근과 뒤넙다리근의 근력이 동심성 훈련군과 비교하여 유의한차 이를 보였다.
본 연구에서도 등속성 편심성 훈련을 중재한 그룹 I, II가 앉은자세 에서 서기 훈련을 중재한 대조군과 비교하여 다리 근활성도에 유의 한 차이를 보였다. 선행연구와 비교하여 훈련속도와 중재기간에 차 이는 있지만 다리 근활성도를 향상시키는 동일한 결과는 등속성 편 심성 훈련이 뇌졸중 환자의 근력 향상을 위해 필요하다는 것을 뒷받 침 해줄수 있다.

Paul 등 ${ }^{23}$ 은 파킨슨 환자 40 명을 대상으로 느린속도를 이용한 근력 강화 훈련군과 일반적인 근력강화 훈련군으로 나누어 12 주 동안 주 2 회 1 일 40 분에 중재한 결과 느린 속도를 이용한 근력강화 훈련군이 무릎관절 근력에서 유의한 향상을 보였고, $\operatorname{Van}$ 등24은 등속성 근력강 화 훈련은 힘-속도(force-velocity) 관계에 의해 동심성 수축에서는 느 린 속도가 편심성 수축에서는 빠른 속도가 근력강화에 효과적이라 고 하였다. 본 연구에서는 느린 속도를 이용한 등속성 편심성 훈련이 다리 근활성도 향상에 유의한 향상을 보여 선행연구와 부분 일치하 였다.

뇌졸중 환자는 포도당과 단백질의 대사작용의 손상과 근원섬유 의 변성으로 근육 덩어리(mass)의 손실로 인해 가로단면적의 감소를 가져오며, ${ }^{25}$ Cadore 등 26 은 빠른 속도를 이용한 등속성 편심성 훈련은 속도에 더 의존적인 type II 섬유를 자극하여 근력을 회복시키고 가로 단면적을 증가시켜 근활성도의 증가를 보였다. 하지만 빠른 속도는 
조직에 과부하를 일으켜 액틴과 미오신의 교차연결이 감소되어 근 수축력의 감소를 나타내기 때문에, ${ }^{27}$ 미오신의 결합력 증가와 type I 섬유와 type II섬유의 동시수축을 유발하는 느린 속도를 이용한 등속 성 편심성 훈련이 다리 근활성도 향상에 효율적이라고 생각된다.

대부분의 뇌졸중 환자는 평균적으로 $0.2 \mathrm{~m} / \mathrm{s}-0.7 \mathrm{~m} / \mathrm{s}$ 의 걷기속도 와 $81.5 \mathrm{~cm}$ 의 한걸음 길이, $79.7 \mathrm{step} / \mathrm{min}$ 의 분속수(cadence)로 시. 공간 적 걸음 요소에 감소를 보이며, 감소된 디딤기와 흔듦기, 조절되지 않 은 분절의 움직임은 같은 연령대의 건강한 대상자와 비교하여 걸음 능력의 감소를 보였고, ${ }^{28}$ Flansbjer 등 29 은 뇌졸중 환자 50 명을 대상으 로 무릎관절의 굽힘근과 폄근의 근력과 걸음능력의 상관관계 연구 에서 근력과 걷기속도, TUG, 계단오르내리기와 유의한 상관관계를 보고하였다.

Lee와 Kang ${ }^{30}$ 은 뇌졸중 환자 20명을 대상으로 등속성 편심성 근력 강화 훈련을 중재한 실험군과 전통적인 물리치료를 중재한 대조군으 로 나누어 6주 동안 주 3회 1일 40분씩 중재한 후 집단 간 비교 결과 실험군이 걷기속도, 계단오르내리기 검사, TUG 검사에서 대조군과 비교하여 유의한 차이를 보였다. Cha 등 ${ }^{31}$ 은 만성 뇌졸중 환자 14 명을 대상으로 느린 속도 $(60 \% \mathrm{sec})$ 를 이용한 등속성 근력강화 훈련군과 빠 른 속도 $(180 \% \mathrm{sec})$ 를 이용한 등속성 근력강화 훈련군으로 나누어 6주 동안 주 3 회 중재한 후 집단 간 비교 결과 느린 속도를 이용한 등속성 근력강화 훈련군이 $10 \mathrm{~m}$ 걷기 검사에서 빠른 속도를 이용한 등속성 근력강화 훈련군과 비교하여 유의한 차이를 보였다. 본 연구에서도 느린 속도를 이용한 등속성 편심성 훈련이 걷기속도 향상에 유의한 향상을 보여 선행연구와 일치하였다.

Kobayashi 등 32 은 등속성 편심성 훈련은 근육, 힘줄, 인대의 뻣뻣함 (stiffness)과 근육의 크기와 근력을 증가시켜 디딤기 동안 무릎관절 근육의 급격한 늘어남(elongation)을 억제하여 무릎관절에 안정성을 제공하고 걸음 동안 정강뼈의 움직임에 영향을 주어 최대 무릎 굽힘 각도의 증가를 보였다. 증가된 최대무릎굽힘각은 빠른 무릎폄을 방 지하여 체중지지의 증가를 통해 디딤기의 시간이 향상되어 걷기속도 가 향상된 것으로 생각된다.

본 연구는 뇌졸중 환자를 대상으로 등속성 편심성 훈련을 중재하 여 다리 근활성도와 걷기속도의 변화를 비교하였고, 치료적 반응을 이끌어내기 위한 효율적인 속도를 알아본 결과 등속성 편심성 훈련 이 대조군과 비교하여 다리 근활성도와 걷기속도에 유의한 차이를 보였으며, 사후검정 결과 느린 속도를 이용한 등속성 편심성 훈련군 이 효율적임을 증명하였다.

본 연구의 제한점은 특정 지역에서 대상자를 선발하였고, 대상자 의 수가 적기 때문에 일반화 하기 어려움이 있었으며, 향후 본 연구를 바탕으로 뇌졸중 환자에게 등속성 편심성 훈련을 통한 근력강화가 심호흡계통의 기능과 삶의 질에 미치는 영향에 대한 추가적인 임상
적 연구가 필요할 것으로 사료된다.

\section{ACKNOWLEDGEMENTS}

본 연구는 2015년 세한대학교의 연구비 지원을 받았음.

\section{REFERENCES}

1. Park SK, Heo JW. Correlation between structures related to movement, activity, and participation in disabled persons living at home. J Kor Phys Ther. 2014;26(2):130-5.

2. Song BK. Effect of somatosensory stimulation on upper limb in sensory, hand function, postural control and ADLs within sensorimotor deficits after stroke. J Kor Phys Ther. 2012;24(5):291-9.

3. Snow LM, Low WC, Thompson LV. Skeletal muscle plasticity after hemorrhagic stroke in rats: influence of spontaneous physical activity. Am J Phys Med Rehabil. 2012;91(11):965-76.

4. Stoeckmann TM, Sullivan KJ, Scheidt RA. Elastic, viscous, and mass load effects on post stroke muscle recruitment and co-contraction during reaching: a pilot study. Phys Ther. 2009;89(7):665-78.

5. Flansbjer UB, Downham D, Lexell J. Knee muscle strength, gait performance, and perceived participation after stroke. Arch Phys Med Rehabil. 2006;87(7):974-80.

6. Chang J, Lee S, Lee M et al. The correlations between gait speed and muscle activation or foot pressure in stroke patients. J Kor Phys Ther. 2009;21(3):47-52.

7. Severinse K, Jakobsen JK, Overgaard K et al. Normalized muscle strength, aerobic capacity, and walking performance in chronic stroke: A population-based study on the potential for endurance and resistance training. Arch Physi Med Rehabil. 2011;92(10):1663-8.

8. Hammami N, Coroian FO, Julia M et al. Isokinetic muscle strengthening after acquired cerebral damage: A literature view. Annals Physi Rehabil Med. 2012;55(4): 279-91.

9. Houchen-Wolloff L, Sandland CJ, Harrison SL et al. Ventilatory requirements of quadriceps resistance training in people with COPD and healthy controls. Int J Chron Obstruct Pulmon Dis. 2014;5(9):589-95.

10. Bae SS, Nam KW, Lee KH. Isokinetic effect of the extensors and flexors in total knee replacement patients. J Kor Phys Ther. 2001;13(1):19-31.

11. Lee H, Kim JM, Noh GB. Effect of concentric isokinetic knee strength training on gait, balance and quality of life in chronic stroke patients. Arch Phys Med Rehabil. 2008;89(11):e140.

12. Guilhem G, Corun C, Guevel A. Neuromuscular and muscle-tendon system adaptations to isotonic and isokinetic eccentric exercise. Ann Phys Rehabil Med. 2010;53(5):319-41.

13. Laroche D, Joussain C, Espagnac C et al. Is it possible to individualize intensity of eccentric cycling exercise from perceived exertion on concentric test?. Arch Phys Med Rehabil. 2013;94(8):1621-7.

14. Dibble LE, Hale TF, Marcus RL et al. High intensity eccentric resistance training decrease bradykinesia and improves quality of life in person with parkinson's disease: a preliminary study. Parkinsionism Relat Disord. 2009;15(10):752-7.

15. Marcus RL, Lastayo PC, Dibble LE et al. Increased strength and physical 
performance with eccentric training in women with impaired glucose tolerance: a pilot study. J Women Health. 2009;18(2):253-60.

16. Valour D, Rouji M, Pousson M. Effects of eccentric training on torqueangular velocity-power characteristics of elbow flexor muscles in older women. Exp Gerontol. 2004;39(3):359-68.

17. Shepstone TN, Tang JE, Dallaire S. Short-term high vs low-velocity is ioskinetic lengthening training results in greater hypertrophy of the elbow flexors in young men. J Appl Physiol. 2005;98(5):1768-76.

18. Han SW, Lee JW. Effects of isokinetic exercise on muscle performance and thickness of quadriceps muscle. J Kor Phys Ther. 2010;22(4):49-55.

19. Roy G, Nadeau S, Gravel D et al. Side difference in the hip and knee joint moments during sit to stand and stand to sit tasks in individuals with hemiparesis. Clin Biomech. 2007;22(7):795-804.

20. Roig M, Macintyre DL, Eng JJ et al. Preservation of eccentric strength in order adults: Evidence, mechanisms and implications for traning and rehabilitation. Exp Gerontol. 2010;45(6):400-9.

21. Clark DJ, Patten C. Eccentric versus concentric resistance training to enhance neuromuscular activation and walking speed following stroke. Neurorehabil Neural Repair. 2013;27(4):335-44.

22. Jegu AG, Pereira B, Andant N et al. Effect of eccentric isokinetic strengthening in the rehabilitation of patients with knee osteoarthritis: Isogo, a randomized trial. Trials. 2014;15:106.

23. Paul SS, Canning CG, Song J et al. Leg muscle power in enhanced by training in people with parkinson's disease: A randomized controlled trial. Clin Rehabil. 2014;28(3):275-88.

24. Van Roie E, Verschueren SM, Boonen S et al. Force-velocity characteris- tics of the knee extension: an indication of the risk for physical frailty in elderly women. Arch Phys Med Rehail. 2011;92(11):1827-32.

25. English C, McLennan H, Thoirs K et al. Loss of skelectal muscle mass after stroke: A systematic review. Int J Stroke. 2010;5(5):395-402.

26. Cadore EL, Gonzalez-Izal M, Pallres JG et al. Muscle conduction velocity, strength, neural activity, and morphological change after eccentric and concentric training. Scand J Sci Sports. 2014;24(5):e343-52.

27. Guilhem G, Guevel A, Cornu C. A standardization method to compare isotonic vs isokinetic eccentric exercise. J Electromyogr Kinesiol. 2010; 20(5):1000-6.

28. Titianova EB, Pitkanen K, Paakkonen A et al. Gait characteristics and functional ambulation profile in patients with chronic unilateral stroke. Am J Phys Med Rehabil. 2003;82(10):778-86.

29. Flansbjer UB, Downham D, Lexell J. Knee muscle strength, gait performance, and perceived participation After Stroke. Arch Phys Med Rehabil. 2006;87(7): 974-80.

30. Lee SB, Kang KY. The effects of isokinetic eccentric resistiance exercise for hip joint on functional gait of stroke patients. J Phys Ther Sci. 2013; 25(9):1177-9.

31. Cha EJ, Oh JK, Yoon JH. Effect of isokinetic exercise on strength of knee muscle, balance, gait ability in the hemiplegic stroke patients. Kor J Sports Sci. 2013;22(3):1173-83.

32. Kobayashi T, Leung AK, Akazawa Y et al. The effect of varying the plantarflexion resistance of an ankle-foot orthosis on knee joint kinematics in patients with stroke. Gait \& Posture. 2013;37(3):457-9. 